\title{
Herophilus, Erasistratus, Aretaeus, and Galen: ancient roots of the Bell-Magendie Law
}

\author{
Matthew I. Tomey, B.A., Ricardo J. Komotar, M.D., AND J Mocco, M.D. \\ Columbia University College of Physicians and Surgeons, New York, New York
}

\begin{abstract}
$\checkmark$ Since the early 19th century, significant controversy has persisted over the competing claims of two men, Charles Bell and François Magendie, to a pivotal discovery: that the dorsal spinal roots subserve sensation, whereas the ventral spinal roots subserve motion. However, the foundations of neuroanatomy on which Bell and Magendie built their research was formed two millennia in advance. Exploration of the work of four ancient scholars-Herophilus, Erasistratus, Aretaeus, and Galen-reveals a remarkable early appreciation of the separate neural pathways (if not the correct physiology) responsible for sensory and motor control. (DOI: 10.3171/FOC-07/07/E12)
\end{abstract}

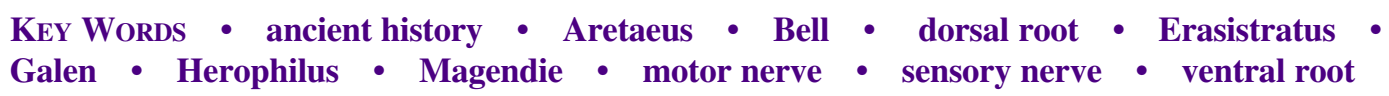

I N THE 185 YEARS since François Magendie published "Expériences sur les fonctions des racines des nerfs rachidiens" in $1822,{ }^{12}$ debate has raged over the intellectual ownership of the landmark discovery that the ventral spinal roots subserve motion and the dorsal roots subserve sensation. Proponents of Sir Charles Bell's priority cite his 1811 Idea of a New Anatomy of the Brain; Submitted for the Observations of his Friends, ${ }^{2}$ an unpublished pamphlet in which he described his experiments in a stunned animal:

On laying bare the roots of the spinal nerves, I found that I could cut across the posterior fasciculus of nerves, which took its origin from the posterior portion of the spinal marrow without convulsing the muscles of the back; but that on touching the anterior fasciculus with the point of the knife, the muscles of the back were immediately convulsed." ${ }^{2}$

Supporters of Magendie's priority point out that in "Expériences" he reported for the first time that transection of the dorsal nerve roots eliminates sensation, transection of the ventral nerve roots eliminates motion, and transection of both nerve roots simultaneously eliminated both motion and sensation. ${ }^{7,12}$

The claims of these two pioneers of spinal cord physiology have been the subject of thorough review and excellent scholarship. Perhaps less attention has been paid, however, to the ancient forebears who laid the groundwork for Bell and Magendie's discovery, to whom Bell pays both homage and criticism in his writings. This essay will review the contributions of four of these early thinkers to what is today often referred to as the BellMagendie Law.

In one of several papers on the nervous system read before the Royal Society of London in 1844, Bell refutes the notion that his ideas on the distinction between motor and sensory nerves were "nothing more than those of Galen."3 As striking as Bell's rebuttal, however, is his acknowledgment of how much Galen and others knew hundreds of years before Bell and Magendie's publications, namely "the division . . . of nerves arising from the brain into those of sensation and of motion, or into hard and soft nerves." 3

Herophilus and Erasistratus laid the foundations of nervous anatomy two millennia earlier. Herophilus, born in Chalcedon, Bithynia (circa $300 \mathrm{BCE}$ ), was a physician in the Hippocratic school, who, along with Erasistratus (circa 260 BCE), helped introduce the discipline of anatomic dissection. ${ }^{5}$ Von Staden ${ }^{10}$ argues "although several significant approximations to the discovery of the nerves were made before Herophilus and Erasistratus, Herophilus has to be credited with first discerning the nerves." Although few of Herophilus' writings and none of Erasistratus' are extant, we can learn much about their contributions from the writings of Galen and Rufus of Ephesus, translated by von Staden and others. ${ }^{10}$ Galen writes in De locis affectis that Herophilus and Eudemus were "the first persons after Hippocrates to record carefully their dissection of the nerves." 16 In De anatomia partium hominis, Rufus ${ }^{16}$ sug- 
gests that Herophilus and Erasistratus were aware of "two kinds of nerves," those that caused "voluntary motion" and those "capable of sensation." The two anatomists differed, however, in their opinion of the origins of nerves. According to Rufus, Erasistratus believed that "the beginnings of the sensory nerves, which are hollow, you could find in the meninges, and those of the motor nerves in the cerebrum and in the cerebellum." Herophilus believed that the nerves of voluntary motion arose from both the "cerebrum" and "the spinal marrow," perhaps foretelling our modern understanding of upper and lower motor neurons. ${ }^{10}$ In their early dissections, Herophilus and others probably confused peripheral nerves with ligaments and tendons, von Staden observes, noting that Herophilus believed that some motor nerves "grow from bone to bone, others from muscle to muscle, and some also bind together the joints." 10 Nonetheless, the clarity of Herophilus' understanding is impressive: although Rufus' extant words are ambiguous, as von Staden observes, he may attribute to Herophilus the concept that "the offshoots from the brain" are "the sensory and voluntary motor nerves, through which sensation and voluntary motion and all action of the body are accomplished."10

Perhaps nowhere are the clinical applications of Herophilus' distinction of sensory and motor nerves more eloquently described than in the writings of Aretaeus of Cappadocia (circa $100 \mathrm{CE}$ ). Describing Aretaeus' work, Mittaire (as cited by Moffat) remarks,

his accuracy is so great that you would imagine he painted and did not write, you would think you did not feed the eyes with an empty picture, but that you were present with the persons afflicted, beheld their various labors, heard their cries, groans and sighs, that you felt yourself affected with horror, and moved with pity, in proportion to the distresses with which they were affected." 14

In his essay "On Palsy," Aretaeus invokes the dissociability of motion and sensation: "Apoplexy, paraplegia, paresis, and paralysis are all of the same kind, and denote a defect of motion, or of sense, or of both, sometimes of the mind, and at other times of the other senses." ${ }^{14} \mathrm{He}$ adds that the "nerves of the head ... may be deprived of sense, but they are not so easily of themselves deprived of motion," whereas "those nerves, which do not belong to the head, are more liable to a deprivation of motion than of sense." 14 Aretaeus was keenly aware of the permanence of nerve lesions: "When Hippocrates says, the whole length, so that it is entirely dead, thereby meaning that it is rendered useless and incurable, he calls this affection of the leg a paraplegia, which in the whole body is a strong apoplexy." "14 Notably, in his eight-volume work, Causes, Symptoms, and Cures of Acute and Chronic Diseases, in which he pairs essays on causes and symptoms with essays on cures, Aretaeus omits the complementary essay on the cure of palsy. ${ }^{14}$

According to Galen, what Herophilus and Erasistratus did not do was define "the beginnings of the nerves that reach each part." In Galen's mind, this was the key to "more successfully treat[ing] the loss of sensation and movement in each part." ${ }^{10}$ Galen (129 CE to $\left.200 \mathrm{CE}\right)$ studied medicine at Smyrna, Corinth, and Alexandria, and made tremendous advances in neuroanatomical knowledge through animal dissections, vivisections, and medical practice, was the first as a surgeon to the gladiators of
Pergamum, and then later served as a personal physician to several Roman emperors. ${ }^{5}$ An encephalocentrist among cardiocentrists, ${ }^{16}$ he proved iconoclastic in his views on the brain's control of motion: "When I tell them this, and add that all voluntary movement is produced by muscles controlled by nerves coming from the brain, they call me a "teller of marvellous tales." ${ }^{8}$ His contributions to our understanding of spinal anatomy and disease were detailed and groundbreaking, from experiments with varying degrees of spinal cord transection, to the identification of 29 pairs of spinal nerves, to his observation of nervous anastomoses. ${ }^{6,13}$ In his study of anastomoses, such as the joining of the third, fourth, and fifth cervical contributions to the phrenic nerve, it is of interest that Galen intimated an understanding of the parallelism of these contributions. As Marketos and Skiadas report, ${ }^{13}$ Galen expressed a belief that Nature had designed nervous anastomoses such that if one contribution should be damaged the contributions of the others would persist.

Flourens ${ }^{9}$ attests to Galen's early awareness of the motor-sensory division in his memoir of Magendie: "Galen was the first to distinguish clearly the nerves from the tendons; the first to see the true origin of the nerves; it was he who first proposed the problem of the separate loss of sensation and of movement: a fundamental problem which it was reserved for our own age to propound anew and to solve." In De locis affectis as translated by von Staden, Galen wonders "why some paralyses destroy only sensation, while others destroy voluntary motion, and others again destroy both." ${ }^{10}$ In fact, Galen alluded specifically to the likelihood that there were unique motor and sensory nerve roots: "Physicians lose sight of the fact that the nerves distributed through the skin of the hand, and by which the faculty of sensation is conveyed to it, have their appropriate roots, and that there are other roots of the nerves by which the muscles are put in motion."

Galen's understanding of nerve function, although prophetic, had its limits. The manner in which the nerves conveyed sensation and put muscles in motion was not yet known to be electrical. Rather Galen subscribed to a theory of psychic pneuma, a substance believed to form in the cerebral ventricles and flow down through the nerves to confer sensation and voluntary movement. ${ }^{4}$ Bell derided this notion as "utterly at variance with anatomy," questioning, "if the brain is the common source of this fluid, where is the necessity for those double and triple sets of nerves which are given to one organ?"3

The degree to which Galen appreciated differences between the nerves of motion and sensation is also unclear, and is challenged by an anonymous writer in 1840: although Galen "stated that the latter are all soft, and the former hard (which is pretty nearly true)" and that "the latter arise from the anterior, and the former from the posterior part of the brain," he "maintained, too, that a nerve which originates, as one of sensation, from the soft part of the brain, may during its course become condensed in its texture and assume the office of a motor nerve."1 Bell remarked in 1844 that "the division proposed by Galen of nerves arising from the brain into those of sensation and of motion, or into hard and soft nerves, implies no more than that he understood there were nerves appropriated to 
the organs of the senses, and nerves for the governance of the muscles." ${ }^{3}$ For Bell, conclusive evidence that Galen did not yet appreciate the division of motor and sensory functions between the ventral and dorsal roots lay in Galen's understanding of ganglia as "given to a nerve when strong motory powers were required." 3

The enigma of the dorsal root ganglia would prove to be the inspiration for Bell and Magendie's ultimate discoveries. ${ }^{15}$ Although Neuburger observes that various animal experiments were undertaken in the centuries after Galen in the hope of further elucidating nervous anatomy and physiology, Galen's viewpoints went largely unchallenged until the 18th century, when in De structura nervorum; Tractatus anatomicus, published in 1779, the German anatomist Procháska asked, "Why do the anterior roots of the spinal nerves pass over the spinal ganglia without saying good morning, and why are the posterior roots alone made to pass through the spinal ganglia?"'15 Why so many years passed before Bell and Magendie's advances on Galen's work could occur is unclear, although Neuburger ${ }^{15}$ suggests that a near dogmatic understanding of the spinal cord as a passive conductor inhibited consideration of the relevance of the arrangement of the spinal roots. Bell notes that Andreas Vesalius (1514-1564 CE) "resisted the authority of Galen on many points, but he adopted, with little variation, both his description of the anatomy of the brain and nerves, and his opinions on the nervous system," and that Albrecht von Haller (1708 CE to $1777 \mathrm{CE}$ ), consistent with Galenic notions of pneumatic flow, concluded that he knew "not a nerve which has sensation without also producing motion." ${ }^{3}$ Even after the publication of the findings of Bell and Magendie, some scientists continued to resist the idea that motion and sensation were discrete. As cited by Hodge ${ }^{11}$ one anonymous author wrote, "there are points in the nervous system where sensation and motion pass over into each other; it is one and the same soul that feels and moves, while if Bell were right two souls, one sensory and another motor, would be conceivable."

The reader interested in the investigations of Bell, Magendie, John Shaw, and Herbert Mayo that have led to our modern understanding of the ventral and dorsal roots is encouraged to explore Cranefield's excellent The Way In and The Way Out, which assembles an extensive collection of the original texts pertinent to the claims of these scientists. ${ }^{7}$ As we consider the contributions of Magendie and Bell to our understanding of the spinal roots and the nervous system in general, we must remember that the foundations of their work were contributed by Herophilus, Erasistratus, Aretaeus, and Galen.

\section{References}

1. Anonymous: Claims of Bell, Magendie, Mayo, etc. to discoveries in the nervous system. Brig For Med Rev:96-1143, 1840. Reprinted in Cranefield PF (ed): The Way in and the Way
Out: Francois Magendie, Charles Bell and the Roots of the Spinal Nerves. Mount Kisco, NY: Futura, 1974, p 28

2. Bell C: Idea of a new anatomy of the brain; submitted for the observations of his friends (1811), in Cranefield PF (ed): The Way In and The Way Out: Francois Magendie, Charles Bell and the Roots of the Spinal Nerves. Mount Kisco, NY: Futura, 1974, p 3

3. Bell C: The Nervous System of the Human Body: as Explained in a Series of Papers Read Before the Royal Society of London. With an Appendix of Cases and Consultations on Nervous Diseases, ed 3. London: Henry Renshaw, 1844

4. Brain P: Galen on Bloodletting: A Study of the Origins, Development, and Validity of His Opinions, with a Translation of the Three Works. Cambridge: Cambridge University Press, 1986, pp 1-14

5. Clarke E: Biographical sketches, in Clarke E (ed): The Historical Development of Experimental Brain and Spinal Cord Physiology before Flourens. Baltimore: Johns Hopkins, 1981, pp 291-374

6. Clarke E: Introduction, in Clarke E (ed): The Historical Development of Experimental Brain and Spinal Cord Physiology Before Flourens. Baltimore: Johns Hopkins, 1981, pp 1-14

7. Cranefield PF: The Way In and The Way Out: Francois Magendie, Charles Bell and the Roots of the Spinal Nerves. Mount Kisco, NY: Futura, 1974

8. Dunn PM: Galen (AD 129-200) of Pergamun: anatomist and experimental physiologist. Arch Dis Childhood Fetal Neonatal E 88: F441-F443, 2003

9. Flourens P: Memoir of Magendie (1858), in Cranefield PF (ed): The Way In and The Way Out: Francois Magendie, Charles Bell and the Roots of the Spinal Nerves. Mount Kisco, NY: Futura, 1974

10. Herophilus: Herophilus. The Art of Medicine in Early Alexandria. Edition, Translation, and Essays by Heinrich von Staden. Von Staden H, translator. Cambridge: Cambridge University Press, 1989

11. Hodge CF: A sketch of the history of reflex action. II. Bell's Law. Am J Psychol 3:343-363, 1890

12. Magendie F: Expériences sur les fonctions des racines des nerfs rachidiens. J Physiol Expér Pathol 2:77-79, 1822

13. Marketos SG, Skiadas PK: Galen: a pioneer of spine research. Spine 24:2358-2362, 1999

14. Moffat J: Aretaeus, Consisting of Eight Books, on the Causes, Symptoms and Cure of Acute and Chronic Diseases; Translated from the Original Greek. London: Logographic Press, 1785

15. Neuburger M: Charles Bell's Discovery, in Clarke E (ed): The Historical Development of Experimental Brain and Spinal Cord Physiology before Flourens. Baltimore: Johns Hopkins, 1981, pp 247-258

16. Rocca J: Galen on the Brain: Anatomical Knowledge and Physiological Speculation in the Second Century AD (Studies in Ancient Medicine). Boston: Brill Academic Publishers, 2003

Manuscript submitted April 23, 2007.

Accepted June 29, 2007.

Address reprint requests to: Matthew I. Tomey, 630 West 168th Street, Box 135, New York, New York 10032. email: mit2103 @ columbia.edu. 